\section{A REVIEW OF THREE HUNDRED CASES} OF BLOOD CHEMISTRY.

By Edward B. Bigelow, M.D., Worcester, Mass.

THIS is the report of a review of the consecutive, chemical examinations of blood from the laboratory of the Worcester City Hospital during a period of eleven months. These specimens of blood were obtained from three hundred adult patients and include the examinations of 458 different specimens. The patients were nearly all hospital cases and seriously sick at the time of examination. The tests were not made routinely by any means upon every admission, but upon selected cases only, whose clinical condition at the time of the examination suggested the possibility of findings that would be of assistance in diagnosis, prognosis or treatment. Oftentimes the negative findings were of as much assistance as the definitely positive results. The blood chemistry report was the most important single factor of our investigation in some cases, but in a considerable majority of the three hundred, it was of minor interest, not to be ranked with the routine history, physical or urine examinations, but rather to be included in the class of the Wassermann reaction, the phthalein and Schlayer nephritic tests, which give assistance in the more complete consideration of a patient's condition.

An estimation of the blood sugar, urea nitrogen and creatinine was made in each case. In addition one hundred and fifty-six cases had an alkali reserve and twenty-nine an uric acid determination. The sugar, urea nitrogen, creatinine and uric acid were determined by the method of Folin and $\mathrm{Wu},{ }^{1}$ and the alkali reserve by the titration method of Van Slyke, Stillman and Cullen. ${ }^{2}$

The blood specimens were obtained before breakfast after a fourteen-hour fast. Powdered potassium oxalate was employed to prevent clotting. Normal blood values for sugar are .09 to .12 of one per cent, for urea nitrogen 14 to 17 mg., for creatinine 1 to $2 \mathrm{mg}$., for uric acid 1 to $3 \mathrm{mg}$. per 100 c.c. of blood; and 80 to 53 c.c. for alkali reserve expressed as the $\mathrm{CO}_{2}$ combining power per 100 c.c. of plasma. One hundred and seven patients had one or more constituents that were pathological in amount.

\section{CREATININE.}

The most striking group with positive findings was that of eighteen cases that had a cre- atinine content of $2.5 \mathrm{mg}$. or more per 100 c.e. of blood. The creatinine of the blood is increased only in certain severe nephritic conditions. It is almost altogether of endogenous origin and therefore cannot be appreciably lessened by a low protein diet. Rarely does recovery take place after this constituent has once been retained in large amounts. Death is nearly always but a matter of days or weeks. This has been demonstrated by Meyers in a report of eighty-five cases with a creatinine value of $5 \mathrm{mg}$. or more, all of whom died except four. ${ }^{3}$

These eigheen cases are summarized in the accompanying table. All except one of them died within a short time. Number 17 is alive now, more than a year after these blood findings, but has, and still continues to require institutional care. These cases from a clinical point of view were recognized in each instance as seriously sick. However, among these three hundred cases, there were several other cases of nephritis that were apparently as sick as this group of patients at the time of their blood examinations, but without any increase in the retention of creatinine and with ensuing improvement. Therefore, the recognition of high creatinine values is of much importance from a prognostic standpoint. It is of interest to note in addition that three of these cases had no casts in the urinary sediment, one had no albumin, and in three the specific gravity was above 1.014, emphasizing the fact that at times negative urinary findings may be misleading in some cases of severe nephritis.

\section{UREA NITROGEN,}

Although the normal value of urea nitrogen is from 13-17 mg. per 100 c.c. of blood, anything below $25 \mathrm{mg}$. in this hospital series I have found to be of small clinical import and have not included as among the cases with pathological findings. Urea nitrogen is largely of exogenous origin, in contradistinction to the endogenous origin of creatinine, and an increase of retention up to $25 \mathrm{mg}$. can generally be overcome, at least to a degree by dietary restrictions. In the table, all of the cases of high creatinine values were accompanied by high retention values of urea nitrogen. As can be noted in the table, there is no parallelism between the values for urea and creatinine, from the determination of one of these constituents the other cannot be estimated with any accuracy. 


\begin{tabular}{|c|c|c|c|c|c|c|c|c|c|c|}
\hline & & & & & TAI & & & & & \\
\hline & $\mathrm{CASE}_{\mathrm{S}}$ & 案 & 总 & 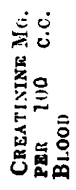 & 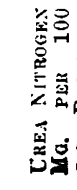 & 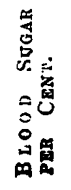 & 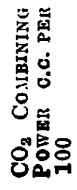 & 悉 & 施 & 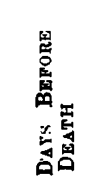 \\
\hline 5 & J. Z. & 29 & $\mathbf{M}$ & 24 & .214 & 0.15 & 29 & $\begin{array}{l}\text { than } \\
10 \\
\text { Less } \\
\text { than }\end{array}$ & $16 \bar{\jmath} / 115$ & 7 \\
\hline $\begin{array}{r}8 \\
12\end{array}$ & $\begin{array}{l}\text { C. H. T. } \\
\text { M. } \mathbf{R} .\end{array}$ & $\begin{array}{l}40 \\
36\end{array}$ & $\underset{\mathbf{M}}{\mathbf{M}}$ & $\begin{array}{l}6 \\
5.6\end{array}$ & $\begin{array}{r}86 \\
219\end{array}$ & $\begin{array}{l}0.14 \\
0.12\end{array}$ & & 10 & $\begin{array}{l}218 / 152 \\
200 / 160\end{array}$ & $\begin{array}{c}23 \\
12 \\
\text { Still }\end{array}$ \\
\hline 17 & M. F. & 28 & $\mathrm{~F}$ & 2.6 & 35 & 0.09 & 39 & 18 & $160 / 110$ & living \\
\hline 34 & C. W. & 67 & II & 10.8 & 118 & 0.13 & & & $200 / 110$ & 1 \\
\hline 54 & G. H. & 54 & $\mathbf{M}$ & 63 & 150 & 0.13 & 44 & 5 & $220 / 118$ & 49 \\
\hline 61 & C. S. & 48 & $\mathbf{M}$ & 5 & 75 & 0.20 & 24 & Trace & $190 / 105$ & 103 \\
\hline 63 & A. C. & 73 & $\mathbf{M}$ & 3.1 & 66 & 0.16 & 53 & & $160 / 94$ & 12 \\
\hline 67 & M. L. & 47 & $\mathbf{M}$ & 3.2 & 75 & 0.14 & & & $98 / 64$ & 2 \\
\hline 92 & P. T. & 51 & $\mathbf{M}$ & 3 & 60 & 0.10 & & 0 & $230 / 144$ & 9 \\
\hline 99 & J. J. & $\mathbf{5 0}$ & $\mathbf{M}$ & 5 & 120 & 0.17 & & & $220 / 160$ & 3 \\
\hline 108 & M. 0 . & 52 & $\mathbf{M}$ & 15 & 150 & 0.16 & 26 & Trace & $162 / 100$ & 35 \\
\hline 38 & J. P. R. & 64 & M. & 3.7 & 60 & 0.20 & & 0 & $225 / 140$ & 25 \\
\hline 70 & E. L. & 40 & $\mathbf{M}$ & 2.5 & 100 & 0.22 & 42 & & $112 / 64$ & 2 \\
\hline & J. C. & 56 & $\mathbf{M}$ & 7.5 & 150 & 0.1 & 65 & & $218 / 100$ & 1 \\
\hline 226 & W. B. & 64 & $\mathbf{M}$ & 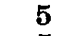 & 100 & 0.12 & 38 & 0 & $140 / 78$ & 19 \\
\hline 241 & McK. & 25 & $\mathbf{M}$ & 5 & 150 & 0. & & & $132 / 80$ & 7 \\
\hline ? & A. N. N. & 36 & $F$ & & 75 & 0.14 & 22 & & & 2 \\
\hline
\end{tabular}

Besides these eighteen cases of high urea other cases, who have been under observation values there were thirty-five others among the a shorter length of time. The blood chemistry three hundred that had from 25 to $60 \mathrm{mg}$. of in these cases was a functional test of value, urea and a retention of creatinine that was less taken in conjunction with other renal function than $2.5 \mathrm{mg}$. Of these thirty-five additional tests and assisted to a truer insight into the concases, fifteen died within a few weeks and most dition of these patients, demonstrating that, alof the remainder were clinically seriously sick though the kidneys were at fault in the particuwith chronic organic ailments, among which lar of a large, persistent albuminuria, in sevnephritis was the primary condition or a seri- eral other particulars they were capable of norous complication.

\section{NEPHRITIS.}

Although in this series there was a large proportion of cases of chronic nephritis, several of them with acute exacerbations, there was only one case of acute nephritis, so-called, with general oedema and albumin, blood and casts in the urine with no apparent etiology other than exposure to cold. The only change in the blood values was an urea nitrogen of $30 \mathrm{mg}$. There was a marked subsidence of symptoms in the next ten days and with it the urea nitrogen sank to $16 \mathrm{mg}$.

While discussing the cases of nephritis with positive blood chemistry findings, several other cases in the series with normal values are noteworthy. Two cases, one followed for twelve years and the other for six with very large traces of albumin at each of many examinations, have continued to work during the time and have no blood nitrogen retention, a good phthalein excretion and response to the Schlayer two-hour test. The same findings were present in three mal excretion.

Another case of apparently severe chronic nephritis, who entered the hospital with general anasarca of three months' standing, a large trace of albumin and many casts in the urine, was discharged much improved after remaining seven weeks. At the height of his symptoms he had no nitrogen retention in the blood and his phthalein excretion was $44 \%$ in two hours, but the kidneys were unable to excrete salt in appreciable amounts by the Schlayer two-hour test diet even after the disappearance of the oedema. Demonstrating again that examinations for nitrogen retention in the blood, phthalein and salt excretion are necessary in certain cases to determine what particular function of the kidney is at fault.

Among the patients in this series brought into the hospital in an unconscious condition, two were of especial interest, because they had a history of sudden onset and were having repeated convulsions, apparently the picture of the symptom iomplex commonly attribhted to achte uremia. Neither had any blood urea ni- 
trogen or creatinine retention and both made rapid symptomatic recoveries from their acute attack, although subsequent urine examinations proved them to be cases of chronic nephritis with good renal functions. In four other cases with convulsions and high urea and creatinine retention values, death ensued soon after the onset of the convuisions. Seemingly, the lack of a nitrogen retention in the blood of cases of uremia may be considered a portent of good omen in prognosis.

\section{URIC ACID.}

No conclusions can be drawn from a review of the blood uric acid determinations in the twenty-nine cases. There was but one case of gout in the series. In this case, upon the first determination, when there had been no acute gouty attacks for months, and upon the second determination some nine months later, and as it happened preceding another acute attack by five days, the uric acid was somewhat increased, being $3.8 \mathrm{mg}$. per 100 c.c. on each occasion. It must be added that this case of typical gout was also one of hypertension with a systolic blood pressure of 190 and a diastolic of 120, no albumin, a few casts, and a phthalein excretion of $35 \%$ in two hours. These findings of an increase of the uric acid are compatible also with those of an interstitial nephritis as well. As pointed out by Meyers, Fine and Lough, ${ }^{4}$ uric acid may be increased in interstitial nephritis before there is any retention of urea or creatinine and its quantitive determination may be employed as an early diagnostic sign of the condition.

\section{MYOCARDITIS.}

There were twenty-nine cases with no arterial hypertension and with no nitrogen retention in the blood, in whom the primary diagnosis was myocarditis, which was severe enough to necessitate hospital and bed treatment. At entrance, in several of these cases with markedly incompetent hearts, the phthalein excretion was so low, that had that been the only test employed to judge of the ability of the kidneys in excreting deleterious products, their competency also would have been considered extremely poor. The low percentage of phthalein excretion was due to secondary passive congestion of the kidneys, and with improvement in the cardiac condition this percentage was much increased. In one case of auricular fibrillation with dyspnoea, anginal pain and vomiting, but no oedema, the phthalein excretion in two hours was less than five per cent., at the same time, there was no nitrogen retention at all, though the percentage of blood sugar was 0.14. In a short time she was symptomatically much improved and in ten days the two-hour phthalein was $35 \%$. So that, though the blood chemistry examination was negative in these cases, in certain of them it was an index of kidney function, that was of more value in prognosis than the phthalein excretion.

\section{ACIDOSIS.}

Acidosis is a condition in which the normal alkalinity of the blood is lowered. The blood actually never becomes acid. This diminution in alkalinity is brought about, as in diabetes, by an increased formation of acid bodies or, as in some cases of nephritis, by a lack of elimination of certain waste products. As previously stated, the normal combining power of the blood for carbon dioxide is from 80 to 53 c.c. per 100 c.c. of plasma. When the range is from 53 to 40 there is a moderate acidosis, no pronounced symptoms; below forty a severe acidosis, a dangerous lowering of the alkali reserve.

Frequent determinations of the alkali reserve of the blood are of importance in the treatment of diabetes mellitus during the stage of decrease in the diet and the determination of the carbohydrate tolerance. It is a much more satisfactory and precise test than the presence or absence of acetone and diacetic acid in the urine. These bodies may be present in the urine and the alkali reserve of the blood show no acidosis. In this series, with this test as an index of the absence of a severe acidosis, the diabetic cases were treated with more assurance and the decrease of diet persisted in, even though there was a marked acetonuria.

Chace and Myers $^{5}$ have demonstrated that fatal cases of chronic nephritis with marked nitrogen retention show a severe acidosis. By reference again to the table this is seen to be the experience in' this series. The exceptions, that is values above forty, were in cases receiving soda bicarbonate medication at the time of the blood examination

In this series of 159 eases, in which the alkali reserve was determined, in only seven others than in the table was it 40 or below. One case of nephritis with an a'kali reserve of 35 
and without nitrogen retention died in three weeks after the determination; a second case with a value of 31 was in a pregnant woman with lethargic encephalitis, who also died in three weeks; a third with 27 , a patient already mentioned in the review, was a case of uremia in convulsions, unconscious and without nitrogen retention and made a good recovery. The four remaining cases each had an alkali reserve of forty. One man convalescing from pneumonia (after treatment) had a normal reading in a few days; a woman, with pernicious vomiting of pregnancy, made a good recovery; the other two were cases of diabetes undergoing the Joslin treatment at the time, who were quickly relieved of the condition without the administration of alkalies, when the condition was recognized by the routine blood examination.

\section{PREGNANCY.}

Seventeen cases of pregnancy are included in the series. In the four normal cases the blood findings were within normal limits with the exception of the urea nitrogen, which was low in each instance, a fact that has been pointed out by Folin. ${ }^{6}$ One case of placenta previa had a urea nitrogen content of $33 \mathrm{mg}$. per 100 c.c. and went on to a normal convalescence. The case of encephalitis lethagica of fatal outcome without retention of sugar or nitrogen, but with an alkali reserve of only 31 , has been noted previously. One case of hydramnios had normal blood values.

There were ten cases of toxemia of pregnancy of the pernicious vomiting type. A series of extremely sick patients. The blood examinations gave figures within normal limits, except that one case at one time had an alkali reserve of 40 and a blood sugar percentage of 0.17. Tileston and Comfort ${ }^{7}$ report normal figures for urea nitrogen in these cases. A high ammonia nitrogen coefficient in the urine was found to be a more dependable, positive index of the severity of the condition as has been previously demonstrated by Losee and Van Slyke. ${ }^{8}$

\section{MISCELLANEOUS CASES.}

There were three cases of brain tumor, two as proven by operation and one by post-mortem examination. The chemical examinations were negative, except that in the case that died and in whom small, red kidneys were found at autopsy, the last blood test two days before death showed a sugar percentage of 0.16. One case had an intermittent glycosuria and a normal blood sugar value.

There were eight cases in whom the final diagnosis was bronchial asthma. The blood examinations were made during the clinical workup. The values were normal in all.

Of eight cases of hypertrophied prostate, in only one was there any abnormality in the blood examinations, a urea nitrogen value of $30 \mathrm{mg}$. per 100 c.c. No radical treatment was caried out and the patient was discharged with an amelioration of symptoms. There were also four cases of septic infection of the bladder or kidneys. One had a urea nitrogen of $32 \mathrm{mg}$. and died within a short time.

Fifty-six cases had a blood pressure of at least $165 \mathrm{~m} . \mathrm{m}$. Hg. systolic or 110 diastolic, besides those listed in the table. Eight of these cases died within a short time after coming under observation. Of these fifty-six cases, with the exception of two with abnormally high urea values, none had more than a miner degree of nephritis. The blood chemistry was one of the functional tests employed in attempting to differentiate these cases as either primary hypertension, or hypertension with myocardial complications from those that had a nephritis in addition.

Of malignant disease there were nine cases that had progressed to cachexia when the blood was examined. In only one was the blood sugar above .11 of one per cent. and then the value was .18. Four had urea nitrogen figures of from 25 to $42 \mathrm{mg}$. per 100 c.c.

Among six cases of severe anemia, five of them of the pernicious type, the blood findings were normal with the exception of one with $25 \mathrm{mg}$. of urea nitrogen. One case of Hodgkin's disease had normal figures.

There were four cases of cerebral infection, who were unconscious at the time the blood examinations were made. Two of them proved to be tubercular meningitis and two lethargic encephalitis. Three had urea nitrogen values of $25 \mathrm{mg}$. or more and three had a hyperglycemia

Five cases of severe furunculosis without glycosuria had normal blood chemistry findings. These tests were performed with the idea that possibly a hyperglycemia might be discovered indicating a prediabetic state, which anticipated, might under appropriate treatment, clear up the furunculosis and avoid severe manifestations of the disease. 


\section{DIABETES,}

In no group of cases among the three hundred were the blood chemistry determinations of more value than in the twenty-five of diabetes mellitus. It is now generally recognized that in the treatment of this disease it is fully as important to moderate the hyperglycemia as to clear up the glycosuria. Freedom from glycosuria is no longer the goal in treatment. Repeated determinations of blood sugar are therefore necessary as guides to obtain the best result in treatment.

Before instituting treatment in these cases an initial blood chemistry examination, including a determination of the alkali reserve, was an important index of the degree of severity of the individual case. Frequent blood analyses were in order, to check up the degree of acidosis and the level of the blood sugar, while the Allen-Joslin treatment was being carried out to clear up the glycosuria, then during the determination of the tolerance for food and later in attempting to moderate the hyperglycemia.

Three cases of diabetes, who had their food tolerance determined and kept within their limits of diet, immediately, upon the onset of influenza, lost their tolerance altogether and again developed a glycosuria, which persisted during the febrile state and for a few days afterward.

One case with a marked family history of diabetes mellitus was found to have a slight persistent hyperglycemia without glycosuria at any time. Upon the application of the blood sugar tolerance test, as described by Janney and Isaacson, ${ }^{9}$ at the end of the first hour the glycemia was .21 of one per cent. and a trace of sugar in the urine, at the end of the second hour it was .12 and still lower at the end of the third and fourth hours without any more glycosuria. After following advice as to a more moderate diet, the blood sugar level diminished and the development of diabetes perhaps has been averted or postponed.

None of the cases in this series came within the classification of renal diabetes. However, However, five of them had a glycosuria without a hyperglycemia. This glycosuria in all of them cleared up within a few days without dietary restrictions.

\section{HYPERGLYCEMIA.}

Besides the diabetic cases, there were fiftytwo others in the series that had an hyperglycemia of .13 of one per cent. or more. Many cases of severe nephritis have high figures for blood sugar as well as for nitrogen. The table demonstrates this, for among those eighteen cases of nephritis with high urea nitrogen and creatinine values, fourteen also have a high value for sugar. Of the remaining thirty-eight cases with a hyperglycemia, twenty-three are cardio-renals, which bears out the statement of Williams and Humphreys, ${ }^{10}$ that high blood sugar levels are associated with severe phases of this condition.

\section{CONCLUSIONS.}

From a review of the blood chemistry in this series of three hundred patients, it is to be concluded, that in general, these examinations, whether they prove to be normal or abnormal, are functional tests of value in the fuller consideration of cases. Prognosis is extremely poor when there is a high retention of creatinine, and rather poor when a high urea retention. The determination of the alkali reserve is valuable in diabetes mellitus and to a lesser degree in nephritis. Repeated blood sugar determinations are invaluable as guides in the treatment of diabetes mellitus.

\section{REFERENCES.}

1 Folin and Wu: Jour. Biol. Chem., Vol. xxxiii, p. 81, May, 1919 - Van Slyke, Stillman and Cullen: Jour. Biol. Chem., Vol. xxxiii,

s. 167, May, 1918. and Clin. Med., Vol. v, p. 566, June, 1920 4 Myers, Fine, and Lough: Arch. Int. Med., Vol. xvii, p. 570 1916.

Chace and Myers: Jour. A. M. A., Vol. lxxiv. p. 641, March 6,1920

Folin: Jour. A. M. A., Vol. Ixix, p. 1212, Oct. 13, 1917.

Tileston and Comfort: Arch. Int. Med., Vol. xiv, p. 620, 1914. ${ }^{8}$ Losee and Van Slyke: Am. Jour. Med. Sci., Vol. cliii, p. 94, 1917.

1917. and Isacson: Jour. A, M. A., Vol. xx, p. 1131, April 20.1918 .

W WiFiams and Humphreys: Arch. Int. Med., Vol. xxiji, pp. 537 $546,559,1918$.

\section{THE NEED OF HEALTH CENTRES.*}

By Eden V. Delphey, M.D., New York,

Chairman Compulsory 'Health and Workmen's Com pensation Insurance Committee of the Medical Society of the County of New York.

From time to time, various and sundry amateur and professional uplifters have endeavored to prescribe for the political, industrial and bodily ills of mankind, and not infrequently their prescriptions are based either upon an inaccurate and incomplete investigation of all the facts in the case, with a resulting inaccurate di-

* Read before the Medical Society of the County of New York at its regular meeting on December 29,1920 , and published in the New York and Illinois State Journals of Medicine. 